\title{
As evidências científicas acerca das complicações do Zika vírus em recém-nascido
}

\author{
Scientific evidence about the complications of Zika virus in newborn \\ Evidencia científica sobre las complicaciones del vírus Zika en recién nascidos
}

Recebido: 11/10/2021 | Revisado: 19/10/2021 | Aceito: 26/10/2021 | Publicado: 29/10/2021

\author{
Antonia Flávia Melo da Silva \\ ORCID: https://orcid.org/0000-0002-2872-8488 \\ Centro Universitário Santo Agostinho, Brasil \\ E-mail: meloflavia794@gmail.com \\ Elayne Azevedo Pereira \\ ORCID: https://orcid.org/0000-0002-2423-2426 \\ Centro Universitário Santo Agostinho, Brasil \\ E-mail: elayne08072017@gmail.com \\ Francisco Adalberto Do Nascimento Paz \\ ORCID: https://orcid.org/0000-0001-6697-1705 \\ Centro Universitário Santo Agostinho, Brasil \\ E-mail: pazadalberto19@ hotmail.com
}

\begin{abstract}
Resumo
A Zika é uma doença febril autolimitada transmitida ao homem através da picada de um mosquito do gênero Aedes, principalmente Aedes aegypti infectado, ou através de uma transmissão vertical da mãe infectada para o feto ou recém-nascido no momento do parto. A maior preocupação na ocorrência da infecção pelo vírus Zika é o acometimento de gestante devido a complicações fetais decorrentes da infecção. Este estudo teve como objetivo identificar através dos achados bibliográficos as principais complicações ao recém-nascido acometido pela microcefalia associada ao Zika, a justificativa deste estudo se dá pela necessidade de identificar quais as complicações que a microcefalia leva para a vida dos recém-nascidos afetados pela doença. Trata-se de uma pesquisa de revisão integrativa da literatura com abordagem qualitativa sobre as implicações decorrente da infecção do Zika vírus nos recém-nascidos, com ênfase na microcefalia. Os artigos incluídos neste estudo apontaram que as alterações mais significativas nos recém-nascidos com microcefalia é o perímetro cefálico e o atraso no desenvolvimento psicomotor, sendo esse último um obstáculo muito vivido também pela família. O presente estudo possibilitou identificar complicações conjugais, decorrentes da chegada de um recém-nascido com microcefalia, e a dificuldade dos profissionais de enfermagem em lidar com o processo de identificação, vigilância e diagnóstico. Dentre as complicações ao recém-nascido, pôde-se observar que as alterações neurológicas e psicomotoras são as mais significativas e que requerem mais atenção.
\end{abstract}

Palavras-chave: Gravidez; Microcefalia; Zika vírus.

\begin{abstract}
Zika is a self-limited febrile disease transmitted to man through the bite of an Aedes mosquito, mainly Aedes aegypti infected, or through vertical transmission from the infected mother to the fetus or newborn at the time of delivery. The biggest concern in the occurrence of Zika virus infection is the impairment of pregnant women due to fetal complications resulting from the infection. This study aimed to identify through bibliographic findings the main complications in newborns affected by microcephaly associated with Zika, the justification of this study is the need to identify which complications microcephaly leads to the lives of newborns affected by the disease. This is an integrative literature review research with a qualitative approach on the implications of Zika virus infection in newborns, with emphasis on microcephaly. The articles included in this study showed that the most significant changes in newborns with microcephaly are head circumference and delay in psychomotor development, the latter being an obstacle often experienced by the family as well. This study made it possible to identify marital complications resulting from the arrival of a newborn with microcephaly, and the difficulty of nursing professionals in dealing with the process of identification, surveillance and diagnosis. Among the complications for the newborn, it could be observed that neurological and psychomotor alterations are the most significant and require more attention.
\end{abstract}

Keywords: Pregnancy; Microcephaly; Zika virus.

\section{Resumen}

Zika es una enfermedad febril autolimitada transmitida al hombre a través de la picadura de un mosquito del género Aedes, principalmente Aedes aegypti infectado o a través de una transmisión vertical de la madre infectada para el feto o recién nacido en el momento del parto. La mayor preocupación en la ocurrencia de la infección por el virus Zika é el acometimiento de gestante debido a complicaciones fetales resultantes de la infección. Este estudio tuvo como objetivo identificar a través de hallazgos bibliográficos las principales complicaciones al recién nacido acometido por 
la microcefalia asociada al zika, la justificación de este estudio se da por la necesidad de identificar cuales complicaciones que la microcefalia lleva para la vida de los recién nacidos afectados por la enfermedad. Tratase de una pesquisa de revisión integrativa de la literatura con abordaje cualitativo sobre las implicaciones resultantes de la infección del Zika virus en los recién nacidos, con énfasis en la microcefalia. Los artículos incluidos en este estudio apuntaran que las alteraciones mas significativas en los recién nacidos con microcefalia es el perímetro cefálico y el retraso en el desarrollo psicomotor, siendo este último un obstáculo muy vivido también por la familia. El presente estudio posibilitó identificar complicaciones conyugales, resultadas de la llegada de un recién nacido con microcefalia, y la dificultad de los profesionales de enfermería al lidiar con el proceso de identificación, vigilancia y diagnóstico. Entre las complicaciones al recién nacido, se puede observar que as alteraciones neurológicas y psicomotoras son las más significativas y que requieren más atención.

Palabras clave: Embarazo; Microcefalia; Zika virus.

\section{Introdução}

A infecção pelo vírus Zika é transmitida ao homem através da picada de um mosquito do gênero Aedes, principalmente Aedes aegypti infectado. Atualmente existem evidências que apontam a transmissão do Zika vírus verticalmente, da mãe infectada com o vírus Zika durante a gestação para o feto ou recém-nascido durante o parto, sendo essa a transmissão congênita (Câmara, 2018).

O vírus Zika (ZIKV) é um arbovírus emergente, do gênero Flavivirus, pertencente à família Flaviviridae, que apresenta relação genética e sorológica com outros flavivírus de importância em saúde pública como o vírus da dengue, o da febre amarela e o do oeste do Nilo, possuindo como principal grupo de riscos Gestantes nos primeiros três meses de gravidez (primeiro trimestre), que é o momento em que o feto está sendo formado (Cunha et al., 2018).

A Zika é uma doença febril autolimitada, tem manifestação de sintomas por 3 a 6 dias, sendo que na maioria dos casos não há manifestação de sintomas, leva a uma baixa necessidade de hospitalização, mas que em mulheres grávidas, pode provocar malformações congênitas subsequentes. As manifestações clínicas das arboviroses em seres humanos podem variar desde doença febril (DF) indiferenciada, moderada ou grave, erupções cutâneas e artralgia (AR), a síndrome neurológica (SN) e síndrome hemorrágica (SH) (Ministério da Saúde, 2017).

Uma das maiores preocupações na ocorrência da infecção pelo vírus Zika é o acometimento de gestante devido a complicações fetais decorrentes da infecção, principalmente no primeiro trimestre, como a microcefalia. O fortalecimento da possível associação entre o vírus Zika e os casos de microcefalia deu-se a partir do achado necroscópico de forte concentração de material viral no tecido de natimortos acometidos pela microcefalia nas regiões afetadas (Câmara, 2018).

A microcefalia é uma malformação congênita em que o cérebro se desenvolve de maneira inadequada: o perímetro cefálico dos recém-nascidos é menor que dois desvios-padrão da média para idade e sexo, podendo levar a alterações cerebrais e problemas no desenvolvimento neurológico. Entretanto, o diagnóstico durante a gestação ainda é impreciso. E é definido quando a circunferência cefálica (CC), medida por ultrassonografia, encontra-se menor que dois ou três desvios padrão abaixo da média, para a idade gestacional (Vargas, 2016).

A confirmação de microcefalia relacionada ao Zika vírus durante a gestação dá-se pelos seguintes critérios: Caso confirmado de feto com alterações pós infecciosas no sistema nervoso central (SNC) relacionadas ao Zika vírus: o feto apresenta alterações no SNC com características de infecção congênita identificada por ultrassonografia (USG) e relato de exantema na mãe durante a gestação, sendo excluídas outras possíveis causas, infecciosas e não infecciosas (Cruz et al., 2016).

A microcefalia causa ainda alterações funcionais e estruturais no organismo humano, sendo definida pela medida do perímetro cefálico (PC) menor que dois ou mais desvios-padrão de referência para o sexo, a idade ou tempo de gestação, sendo igual ou inferior a 31,9 cm para meninos e 31,5 para meninas, ambos nascidos a termo. A infecção pelo vírus Zika tornou-se um problema de saúde no Brasil a partir de 2015 quando houve a identificação do surto da doença na região do nordeste (Cruz et al., 2019). 
De acordo com o MS (Ministério da saúde) a microcefalia é um problema de saúde pública que pode causar serias anormalidades neurológicas, sendo uma malformação congênita em que o cérebro não se desenvolve de maneira adequada, sendo caracterizada por um perímetro cefálico inferior ao esperado para a idade e sexo. Os recém-nascidos (RN) com microcefalia podem apresentar atraso no desenvolvimento e incapacidade intelectual, bem como podem desenvolver convulsões e incapacidades físicas, dificuldades auditivas e visuais (Ministério da Saúde, 2020).

Muito embora o período de emergência tenha sido encerrado, novos casos de síndrome congênita associada à infecção pelo vírus Zika (SCZ) continuam ocorrendo no país. Mesmo após passados 5 anos da epidemia do Vírus Zika no Brasil, ainda existem desafios a serem enfrentados como a descrição da história natural da doença, definição e padronização de um código da Classificação Estatística Internacional de Doenças e Problemas Relacionados à Saúde (CID) para auxiliar na sua identificação e monitoramento, ampliação do acompanhamento do crescimento e desenvolvimento das crianças (Alves \& Scherrer, 2018).

O papel educacional da enfermagem é fundamental e consiste na orientação de famílias com crianças portadoras de microcefalias, principalmente quanto a prevenção e a importância do pré-natal, pois assim a gestante poderá receber o diagnóstico precoce e pronta atenção. O enfermeiro pode auxiliar na identificação dos sintomas da infecção pelo vírus Zika em gestantes, além da deteç̧ão de alterações no crescimento, nutrição e desenvolvimento neuropsicomotor da criança, que deve ser avaliada constantemente em consultas nas Unidades Básicas de Saúde (UBS), devido a possibilidade de complicações (Queiroz et al., 2019).

Diante do exposto, esse estudo teve como objetivo analisar as consequências e implicações do Zika vírus em recémnascidos especificando a relação entre o vírus Zika e a microcefalia.

\section{Metodologia}

O presente estudo trata-se de uma revisão integrativa da literatura. Nesta abordagem é possível sintetizar o aprendizado de um determinando assunto, facilitando assim sua visa reunir compreensão. Esse método resultados de pesquisas sobre um delimitado tema ou questão, de maneira sistemática e ordenada, aprofundando o conhecimento do tema investigado (Mendes, Silveira \& Galvão, 2008). Revisar a literatura é imprescindível no desenvolvimento de estudos acadêmicos e científicos. Realizar uma revisão de literatura evita a duplicação de pesquisas ou, quando for de interesse, reaproveita a aplicação de pesquisas em diferentes escalas e contextos (Galvão \& Ricarte, 2019).

A coleta de dados foi realizada durante o mês de julho de 2021 por meio de levantamento bibliográfico na Biblioteca Virtual em Saúde (BVS), foram selecionados artigos das bases de dados Medical Literature Analysisand Retrieval System Online (MEDLINE), Literatura Latino Americana e do Caribe em Ciências da Saúde (LILACS), Base de Dados de Enfermagem (BDENF), Bibliografía Nacional em Ciencias de la Salud Argentina (BINASCIS), Repositório Institucional da OPAS (PAHO - IRIS).

Os filtros usados para a condensação dos achados bibliográficos foram: ano de publicação, tipo de estudo, assunto principal e textos disponíveis na íntegra. Para o levantamento dos artigos foram usados os descritores controlados "microcefalia" e "Zika Vírus", sendo feito inicialmente uma busca isolada onde o descritor microcefalia apresentou 6.472 resultados e Zika vírus 10.492 artigos, ao utilizar a ferramenta de busca com uso do indicador booleano "and" os termos cruzados apresentaram 241 publicações, ao aplicar os filtros considerando assim uma melhor síntese para atender os objetivos da pesquisa o número de artigos foi reduzido para 100. Um fluxograma do Prisma foi elaborado para ilustrar o processo de seleção destes estudos. 
Fluxograma 1 - Dados do levantamento bibliográfico, 2021.

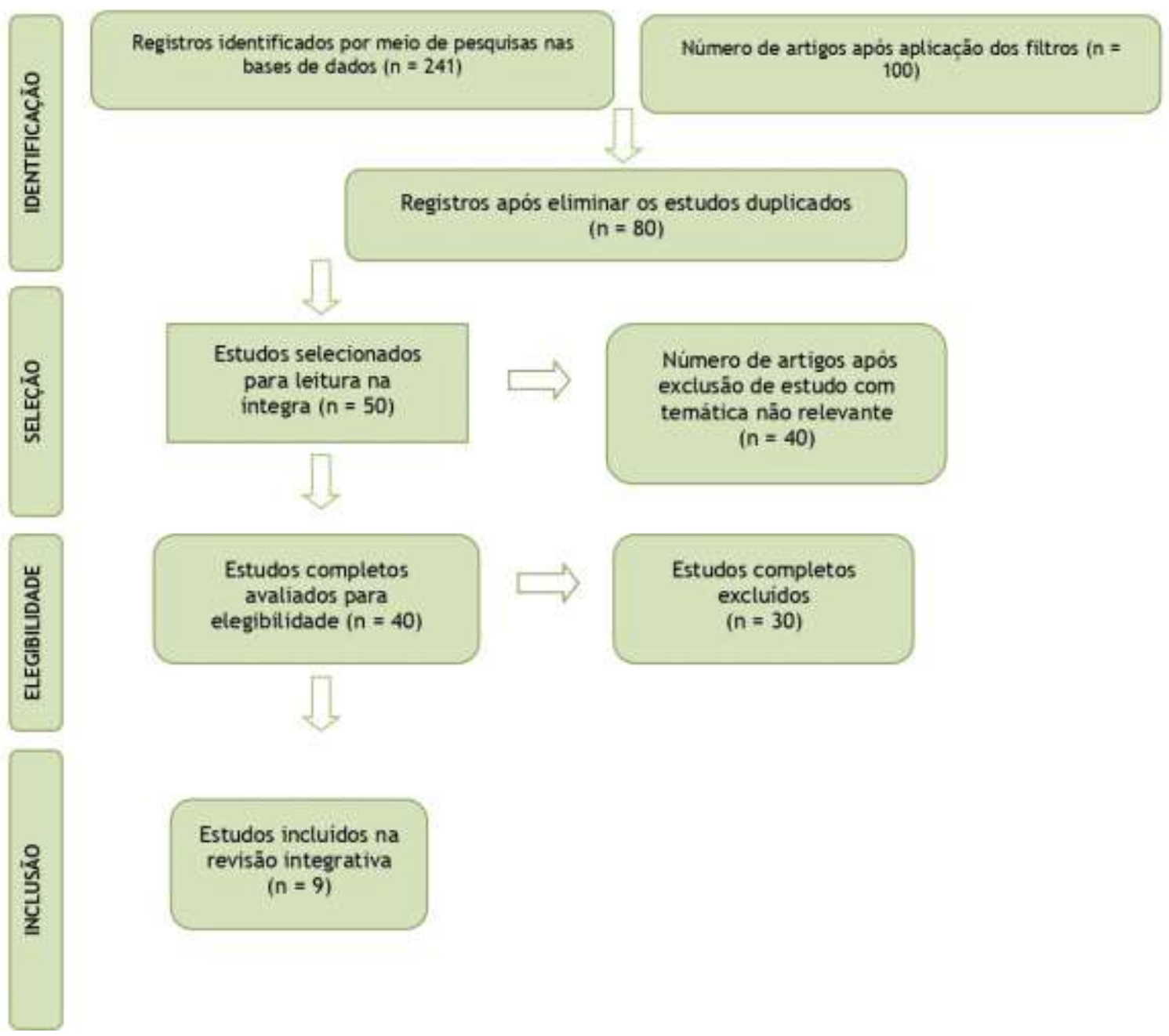

Fonte: PRISMA Flay Diagram.

Para formular a questão de pesquisa, utilizou-se a ferramenta PICo, na qual P é a População, I a variável de interesse e Co o contexto, desta forma, têm-se a seguinte estrutura: P: complicações do zika vírus em recém-nascido; I: prevenção, diagnóstico e tratamento; Co: assistência de enfermagem, resultando na questão norteadora: Quais as evidencias cientificas acerca das complicações do zika vírus em recém-nascido?

\section{Resultados e Discussão}

Após análise dos 16 artigos, 2 não estavam disponíveis para acesso público, 2 encontravam-se duplicados e 3 não apresentavam resultados relevantes aos questionamentos levantados pelas pesquisadoras. Desta forma, foram incluídos na revisão integrativa 09 artigos que apresentam temáticas com ponto de vista similar ao que foi abordado. Estes foram organizados e dispostos na tabela a seguir. 
Tabela: Descrição dos artigos selecionados conforme título, ano de publicação, objetivos e principais resultados.

\begin{tabular}{|c|c|c|}
\hline $\begin{array}{l}\text { TÍTULO/ ANO DE } \\
\text { PUBLICAÇÃO }\end{array}$ & OBJETIVOS & PRINCIPAIS RESULTADOS \\
\hline $\begin{array}{l}\text { Experiências de pais de crianças } \\
\text { nascidas com microcefalia, no } \\
\text { contexto da epidemia de Zika, a } \\
\text { partir da comunicação do } \\
\text { diagnóstico (2019) }\end{array}$ & $\begin{array}{l}\text { Compreender como os pais das crianças com } \\
\text { microcefalia receberam este diagnóstico }\end{array}$ & $\begin{array}{l}\text { A comunicação da notícia não atendeu às expectativas } \\
\text { dos pais, sendo omitida pelos profissionais, por falta de } \\
\text { evidências ou por ser considerada uma abordagem } \\
\text { traumática. As formas de comunicação do diagnóstico } \\
\text { da microcefalia aos pais influenciaram nos modos de } \\
\text { aceitação e enfrentamento da situação. Os pais relataram } \\
\text { ainda a ausência do acolhimento e instruções acerca dos } \\
\text { cuidados necessários. }\end{array}$ \\
\hline $\begin{array}{l}\text { Crises convulsivas em neonato } \\
\text { com microcefalia associada à } \\
\text { infecção pelo Zika vírus (2019) }\end{array}$ & $\begin{array}{l}\text { Analisar, a partir do caso de recém-nascido } \\
\text { com microcefalia relacionada à infecção do } \\
\text { vírus Zika, suas características clínicas e } \\
\text { implicações para o cuidado em saúde e } \\
\text { enfermagem }\end{array}$ & $\begin{array}{l}\text { Foi evidenciado no estudo, a importância do processo } \\
\text { de sistematização de enfermagem no cuidado à criança } \\
\text { com microcefalia, favorecendo o processo de trabalho, a } \\
\text { identificação precoce de sinais clínicos. }\end{array}$ \\
\hline $\begin{array}{l}\text { Vivências de cuidadoras sobre o } \\
\text { cuidado de crianças com } \\
\text { microcefalia (2020) }\end{array}$ & $\begin{array}{l}\text { Descrever experiências relacionadas à } \\
\text { vivência de cuidadoras sobre o cuidado de } \\
\text { crianças com microcefalia associada ao Zika } \\
\text { vírus }\end{array}$ & $\begin{array}{l}\text { O distanciamento tanto da figura paterna quanto dos } \\
\text { demais membros familiares e amigos provoca } \\
\text { sentimentos de abandono que geram mudanças } \\
\text { definidoras na vida das cuidadoras, como a perda da } \\
\text { autonomia, o afastamento da sua identidade enquanto } \\
\text { mulher e a sobrecarga de responsabilidades }\end{array}$ \\
\hline $\begin{array}{l}\text { Descrição dos casos de } \\
\text { síndrome congênita associada à } \\
\text { infecção pelo ZIKV no estado } \\
\text { de São Paulo, no período } 2015 \text { a } \\
2017 \text { (2018) }\end{array}$ & $\begin{array}{l}\text { Caracterizar os casos de síndrome congênita } \\
\text { associada à infecção pelo ZIKV (SCZ) e } \\
\text { outras etiologias infeciosas, residentes no } \\
\text { estado de São Paulo, Brasil, no período de } 30 \\
\text { de outubro de } 2015 \text { a } 30 \text { de junho de } 2017\end{array}$ & $\begin{array}{l}\text { Encontrou-se uma proporção de } 63,5 \% \text { (146/230) de } \\
\text { casos de síndrome congênita infecciosa, incluídos os } \\
\text { casos confirmados de SCZ, casos confirmados sem } \\
\text { identificação etiológica e casos confirmados de } \\
\text { síndrome congênita associada a algum STORCH. }\end{array}$ \\
\hline $\begin{array}{l}\text { Dinâmica familiar de criança } \\
\text { com a síndrome congênita do } \\
\text { Zika vírus no Município de } \\
\text { Petrolina, Pernambuco, Brasil } \\
\text { (2020) }\end{array}$ & $\begin{array}{l}\text { Analisar a dinâmica familiar de criança com a } \\
\text { síndrome congênita associada ao Zika vírus } \\
\text { (SCZV) no Município de Petrolina, } \\
\text { Pernambuco }\end{array}$ & $\begin{array}{l}\text { Uma criança com diagnóstico de SCZV traz importantes } \\
\text { mudanças na dinâmica familiar, como maior } \\
\text { dependência da criança ao cuidador, que } \\
\text { majoritariamente é do gênero feminino, aumento de } \\
\text { gastos financeiros devido à necessidade de } \\
\text { deslocamento para os serviços de saúde }\end{array}$ \\
\hline $\begin{array}{l}\text { Estimulação precoce diante do } \\
\text { desenvolvimento da criaç̧a } \\
\text { com microcefalia: percepção } \\
\text { materna (2019) }\end{array}$ & $\begin{array}{l}\text { Conhecer a percepção materna acerca da } \\
\text { estimulação precoce e sua repercussão no } \\
\text { desenvolvimento da criança com microcefalia } \\
\text { associada ao Zika vírus }\end{array}$ & $\begin{array}{l}\text { Ficou perceptível que as mães reconheceram a } \\
\text { importância de estimular os(as) filhos(as) em casa, } \\
\text { assim como demonstraram buscar realizar cuidados que } \\
\text { visam melhorar o desenvolvimento das crianças, as } \\
\text { mães referiram que o tempo de estimulação com cada } \\
\text { profissional, é considerado por elas como insuficiente } \\
\text { para atender às necessidades de seus filhos. }\end{array}$ \\
\hline $\begin{array}{l}\text { Itinerário da criança com } \\
\text { microcefalia na rede de atenção } \\
\text { à saúde }(2020)\end{array}$ & $\begin{array}{l}\text { Investigar o itinerário terapêutico de crianças } \\
\text { com microcefalia associada ao Zika na rede } \\
\text { de atenção à saúde; e descrever a vivência das } \\
\text { mães em relação ao itinerário percorrido para } \\
\text { o tratamento de seus filhos }\end{array}$ & $\begin{array}{l}\text { Houve dificuldade para a identificação da microcefalia, } \\
\text { acarretando atraso do diagnóstico e do início do IT e } \\
\text { possível interferência no progresso das habilidades } \\
\text { neuropsicomotoras da criança. Foi evidenciado o } \\
\text { acúmulo de demandas, exigindo redefinição dos papéis } \\
\text { das pessoas que se envolverão na prática do cuidado. }\end{array}$ \\
\hline $\begin{array}{l}\text { Microcefalia no Estado de } \\
\text { Pernambuco, } \\
\text { características } \\
\text { e avaliação da dasil: } \\
\text { diagnóstica dos pontos de corte } \\
\text { adotados para } \\
\text { caso notificação de } \\
\text { (2016) }\end{array}$ & $\begin{array}{l}\text { Realizar uma análise crítica e continuada de } \\
\text { um parâmetro para a vigilância de casos de } \\
\text { microcefalia em recém-nascidos, no contexto } \\
\text { da atual epidemia. Exploração de outros } \\
\text { critérios clínicos e/ ou fenotípicos, bem como } \\
\text { achados em exames por imagem, na definição } \\
\text { de um padrão-ouro mais acurada. }\end{array}$ & $\begin{array}{l}\text { Dentre os } 684 \text { casos notificados, } 599 \text { foram recém- } \\
\text { nascidos a termo/pós - termo e } 85(12,4 \%) \text { pré-termo, } \\
\text { percentual similar ao da população. Dentre os recém- } \\
\text { nascidos pré-termo, sete tinham entre } 22 \text { e } 31 \text { semanas } \\
\text { de gestação. Predominaram notificações de casos do } \\
\text { sexo feminino ( } 423 \text { casos), que representaram } 62 \% \text { do } \\
\text { total. }\end{array}$ \\
\hline $\begin{array}{l}\text { Microcefalia e dinâmica } \\
\text { familiar: a percepção do pai } \\
\text { frente à deficiência do filho } \\
(2016)\end{array}$ & $\begin{array}{l}\text { Relatar as reações diante do diagnóstico de } \\
\text { microcefalia, negação e estratégias de } \\
\text { enfrentamento, falta de informação, dinâmica } \\
\text { familiar após a microcefalia, preconceito, } \\
\text { inclusão, limitações funcionais da criança, } \\
\text { onus familiar com a deficiência, dificuldade } \\
\text { de conciliar as atividades laborais com a } \\
\text { função paterna }\end{array}$ & $\begin{array}{l}\text { Os entrevistados têm entre } 20 \text { e } 35 \text { anos, com pouco } \\
\text { nível de escolaridade. Em quatro casos, as crianças com } \\
\text { limitações funcionais eram filhos únicos. Nenhum dos } \\
\text { pais entrevistados tinha outro filho } \\
\text { com deficiência, tampouco tinha acompanhamento } \\
\text { psicológico. Algumas esposas dispunham desse serviço: } \\
\text { quatro são acompanhadas pelo psicólogo. } 80 \% \text { moram } \\
\text { na zona rural. E a renda da família é de apenas } 1 \text { salário- } \\
\text { mínimo. }\end{array}$ \\
\hline
\end{tabular}


Na tabela estão dispostos os 09 artigos inclusos nessa revisão da literatura, estes apresentam semelhantes percepções acerca das consequências do Zika vírus associado a microcefalia em recém-nascidos. Os achados dessa pesquisa dividem-se em algumas temáticas relevantes. Diante disso, dividiu-se os principais resultados em três eixos categóricos apresentados a seguir:

\section{Eixo Categórico: Consequências da Infecção Associada ao Zika Vírus}

Os estudos demonstraram que a relação entre os casos de microcefalia e a infecção pelo vírus Zika foi primeiramente descrita no Brasil, quando se percebeu um aumento do crescimento no número de casos de crianças brasileiras com essa enfermidade e alterações no sistema nervoso central (SNC), concomitante a ocorrência de uma doença exantemática febril ocasionada pelo vírus. De acordo com Martins et al. (2018), em 2015 foram realizados exames laboratoriais em várias unidades da federação e em outros países, onde houve o maior número de casos confirmados com infecção congênita ZIKV (SCZ), com maior incidência em recém-nascidos/crianças.

De acordo com Oliveira et al. (2018) o maior risco de microcefalia associado com a infecção por Zika ocorre no primeiro trimestre da gestação, sendo biologicamente plausível, uma vez que no primeiro trimestre da gravidez ocorre o período embrionário de maior risco para múltiplas complicações decorrentes de processo infeccioso.

Conforme observado nos estudos realizados nesta pesquisa constatou-se que as crianças que nasceram com microcefalia, os seus primeiros meses de gestação corresponderam ao período de maior circulação do vírus Zika na região nordeste e que de acordo com os casos estudados houve um número significativo de recém-nascido/crianças com microcefalia grave (Pedrosa et al., 2019).

Dentre os estudos inclusos nessa pesquisa, evidenciou-se que a maioria dos casos de microcefalia estão diretamente associada ao Zika Vírus. Onde houve atraso no desenvolvimento psicomotor, em alguns casos foram observados também crises convulsivas e alteração do perímetro cefálico. Em relação ao peso e tempo de gestação não houve muitas alterações, sendo a maiorias dos recém-nascidos a termo e pesando mais de $2,500 \mathrm{~kg}$.

\section{Eixo Categórico: Experiência e Conduta dos Profissionais de Saúde Frente a Microcefalia}

A partir dos artigos revisados constatou-se que há uma deficiência de informações no momento da comunicação da microcefalia aos pais, seja pelo despreparo dos profissionais ou até mesmo pela falta de informações que havia na época. O atraso na comunicação resultou na demora para iniciar o tratamento adequado, e dificultou a aceitação dos familiares.

Diante da dificuldade em identificar o quadro microcefálico, percebeu-se a necessidade de um protocolo sistematizado que facilite ao profissional a rápida descoberta da microcefalia. Alguns pais sentiram que o tratamento oferecido foi insuficiente na estimulação da criança com microcefalia. Foi observado ainda que o abandono paterno e/ou familiar gera um sentimento de desprezo que muitas vezes gera a perda de autonomia da mãe, uma vez que essa passa a ter sua atenção exclusivamente voltada a criança, sendo a única responsável.

Ficou evidenciado que os profissionais precisam orientar a população a evitar horários e lugares com presença de mosquitos; utilizar continuamente roupas que protejam partes exposta do corpo, especialmente a gestante, cobrindo braços e pernas; alertar a gestante e acompanhante sobre as medidas de controle vetorial (eliminar na casa e terrenos possíveis criadouros do mosquito). Deve-se estimular o uso de mosquiteiros ou telas e repelentes devidamente registrados pela Agência Nacional de Vigilância Sanitária (Oliveira et al., 2018).

De acordo com Sousa et al. (2016), é necessária uma análise crítica e continuada de um parâmetro de intervenções e vigilância de casos de microcefalia em recém-nascidos, no contexto atual. Ficou evidenciado que é fundamental explorar outros critérios clínicos, uma vez que o principal achado clínico é o perímetro cefálico. Oliveira et al. (2018) concorda que a 
microcefalia está associada a outros aspectos, sendo as mães de recém-nascidos/ crianças com microcefalia associadas ao Zika vírus, jovens, agricultoras que possuem renda per capita equivalente a um salário-mínimo e que vivem em situações de vulnerabilidade.

Segundo Pereira et al. (2019), a principal característica da microcefalia é o perímetro cefálico menor que $32 \mathrm{~cm}$, de acordo com estudos nessa pesquisa foi possível observar um caso de um neonato com crises convulsivas, com diagnóstico feito através de exames de imagem. O medicamento de escolha foi o fenobarbital, após passar sete dias na unidade de terapia intensiva, verificou-se uma significativa melhora. Não há estudos com protocolos acerca do tratamento de convulsões relacionada a microcefalia, dificultando, portanto, o trabalho das equipes ao se deparar com este tipo de caso.

Souza et al. (2016) possui uma visão diferenciada sobre o processo de vigilância de casos de microcefalia em recémnascidos. Sousa et al. (2016) afirma que é necessária uma investigação através da assistência dos casos, baseando-se por achados em exames por imagem, com um padrão mais acurado de investigação.

A infecção congênita associada ao Zika vírus é um problema de saúde de publica e que nesta pesquisa pôde-se perceber que as áreas mais atingidas são as mais carentes, nas regiões do nordeste, onde existe uma carência de informações, orientação, acesso a unidade básica de saúde e em que a população não possuem saneamento básico e métodos de vigilância ativos e presentes (Sá et al., 2020).

\section{Eixo Categórico: Mudanças no Eixo Familiar após Descoberta do SCZV}

Evidenciou-se através dessa pesquisa que uma criança com deficiência não é o fator que determine crise conjugal, porém existem características individuais de cada casal que são ressaltadas com a chegada de uma criança, sobretudo com SCZV e suas necessidades. Considerando os estudos realizados nesta pesquisa, compreende-se que há um distanciamento conjugal (Pedrosa et al., 2019).

De acordo com Oliveira et al. (2018) as mulheres são majoritariamente afetadas a partir do diagnóstico, uma vez que essas têm a maior responsabilidade nos cuidados ao recém-nascido, as participantes da pesquisa tinham entre 15 e 45 anos de idade, ensino médio completo e donas de casa. A notícia de que os filhos tinham microcefalia foi inesperada para 14 entrevistados, os outros já tinham tido algum contato com a doença durante a epidemia, apenas 5 dos casos foram confirmados durante a gravidez. Três problemas principais foram observados a partir deste estudo: omissão do diagnóstico, processo de comunicação do diagnóstico e antecipação de prognóstico.

Foram pontuadas mudanças no comportamento paterno e até mesmo abandono do lar, onde a família sofre impactos decorrentes dessas mudanças. De acordo com Sá et al. (2020) dentre as mudanças enfrentadas pelas famílias de crianças SCZV, encontra-se o aumento nos gastos financeiros, e pôde-se perceber que, na maioria dos casos, esse incremento está relacionado com as demandas para um melhor desenvolvimento da criança. A aquisição de medicamentos e brinquedos, bem como moradia, transporte e alimentação.

Cajuhi et al. (2020) corroborando com os resultados apontados por Oliveira et al. (2018) mostra que a maioria das mães com filhos microcefálicos são jovens, donas de casa e a principal cuidadora dos seus filhos. Cajuhi et al. (2020) assim como os outros estudos citados mostra a perda da autonomia feminina após o diagnóstico de microcefalia, já que estas abdicam de suas vidas antigas para serem cuidadoras em tempo integral

A pesquisa de Félix e Farias (2018) mostrou, pelos relatos dos pais, os efeitos da microcefalia na família, descobrindo como o pai experiencia a notícia de deficiência dos filhos, como ele se implica no cuidado e suporte familiar, possibilitando aos profissionais da saúde lançar estratégias de acolhimento e atendimento voltadas não somente para as mães. Esses homens são seres que precisam de auxílio, apoio, implicando qualidade de vida para eles e suas famílias, tendo em vista que, nas relações familiares, um membro influencia o outro. 


\section{Conclusão}

O presente estudo possibilitou a identificação de complicações existentes por meio da relação entre microcefalia e o vírus Zika. Evidenciaram-se as dificuldades conjugais com a chegada de um recém-nascido com microcefalia, e a dificuldade dos profissionais de enfermagem em lidar com o processo de identificação, vigilância e diagnóstico.

Dentre as complicações ao recém-nascido, pôde-se observar que as alterações neurológicas e psicomotoras são as mais significativas e que requerem mais atenção, o acompanhamento e estímulo desde o nascimento é o principal tratamento na microcefalia, uma vez que cada caso responde de forma diferente e, portanto, requer um estímulo diferente.

No levantamento de dados evidenciou-se a necessidade de novas medidas que possibilitem o pai a participar de todo o processo desde a investigação até o diagnóstico, com intuito de orientar e evitar possível abandono do lar, uma vez que foi verificado na pesquisa que a mãe na maioria dos casos sofre abandono, tornando-se única responsável pelo recém-nascido com microcefalia.

Mediante esta pesquisa, os resultados poderão beneficiar os profissionais de enfermagem quanto à abordagem aos casos de microcefalia em recém-nascidos, implementando novas ações que possibilite uma boa comunicação com a família, assim como auxiliar o processo de vigilância em saúde no rastreamento, investigação, diagnóstico, monitoramento e ampliação do acompanhamento e desenvolvimento das crianças afetadas.

Considera-se que, os resultados encontrados contribuam futuramente para que essas ações sejam incrementadas e que auxilie os profissionais e acadêmicos com uma nova percepção de intervenções, e de como lidar com a família com uma criança com infecção associada ao vírus Zika.

Espera-se com este estudo despertar o interesse pela temática, por novas pesquisas, de forma a contribuir para o ensino e prática profissional, estimulando profissionais de saúde a produzir novas pesquisas e conhecimentos acerca da associação entre microcefalia e vírus Zika.

\section{Referências}

Alves, C. R. L., \& Scherrer, I. R. S. (2018). Semiologia da criança e do recém-nascido. NESCON.

Cajuhi, A. S., Suto, C. S. S., Mercês, A. E. D., Oliveira, J. S. B., \& Costa, L. E. L., Nascimento, R. C. D., \& Linhares, T. P. S. (2020). Vivências de cuidadoras sobre o cuidado de crianças com microcefalia. Rev. Enferm. UFPE Online. 14, 1-7.

Câmara, A. P. B. (2018). Microcefalia em recém-nascidos: antes e após epidemia pelo vírus Zika, 2018. Dissertação de mestrado, Universidade Federal do Maranhão, São Luís, Maranhão, Brasil.

Cruz, R. S. B. L. C., Batista, M. F., Caminha, M. F., \& Souza, E. S. (2016). Protocolos de atenção pré-natal à gestante com infecção por Zika e crianças com microcefalia: justificativa de abordagem nutricional. Rev. Bras. Saúde Mater. Infant. 16(1), 95-102.

Félix, V. P. S. R., \& Farias, A. M. (2019). Microcefalia e dinâmica familiar: a percepção do pai frente à deficiência do filho. Cadernos de Saúde Pública. 34(12), 1-11.

Galvão, M. C. B., \& Ricarte, I. L. M. Revisão sistemática da literatura: conceituação, produção e publicação. Logeion: Filosofia da informação. 6(1), 57-73.

Martins, R. S., Fróes, M. H., Saad, L. C, Ignácio, S. M. J., Prado, W. D. A., Figueiredo, E. M., Sato, H. K., Ciccone, F. H., Guimarães, T. C. \& Katz, G. (2017). Descrição dos casos de síndrome congênita associada à infecção pelo ZIKV no estado de São Paulo, no período 2015 a 2017 . Epidemiologia $e$ Serviços de Saúde. 27(3), 1-10.

Mendes, K. D. S., Silveira, R. C. C. P., \& Galvão, C. M. (2008). Revisão integrativa: método de pesquisa para uma incorporação de evidências na saúde e na enfermagem. Texto \& contexto-enfermagem. 17(4), 758-764.

Ministério da Saúde. (2020). Situação epidemiológica da síndrome congênita associada à infecção pelo vírus Zika em 2020 , até a SE 45. https://www.gov.br/saude/ptbr/assuntos/media/pdf/2020/dezembro/11/boletim_epidemiologico_svs_47.pdf

Ministério da Saúde. (2017). Vírus Zika no Brasil A resposta do SUS. http://bvsms.saude.gov.br/bvs/publicacoes/virus_zika_brasil_resposta_sus.pdf

Moher, D., Liberati, A., Tetzlaff, J., Alteman, D. G., \& Group, P. (2009). Reprint - Preferred Reporting Items for Systematic Reviews and Meta-Analyses: The PRISMA Statement. Physical therapy, 89(9), 873-880.

Oliveira, B. S. B., Melo, F. M. S., Oliveira, R. K. L., Neta, J. F. F., Monteiro, F. P. M. \& Joventino, E. S. (2019). Estimulação precoce do desenvolvimento da criança com microcefalia: percepção materna. Revista Brasileira de Enfermagem. 72, 146-153. 
Research, Society and Development, v. 10, n. 14, e161101421674, 2021

(CC BY 4.0) | ISSN 2525-3409 | DOI: http://dx.doi.org/10.33448/rsd-v10i14.21674

Oliveira, P. S. (2019). Experiências de pais de crianças nascidas com microcefalia, no contexto da epidemia de Zika, a partir da comunicação do diagnóstico. Tese de doutorado, Universidade Federal do Maranhão, São Luís, Maranhão, Brasil.

Pedrosa, R. K. B., Guedes, A. T. A., Soares, A. R., Vaz, E. M. C., Collet, N., \& Reichert, A. P. S. (2020). Itinerário da criança com microcefalia na rede de atenção à saúde. Escola Anna Nery. 24(3), 1-8.

Pereira, L. P., Almeida, A. O. L. C., Lima, C. C. O. J., Santos, J. B., Barbosa, M. S., \& Felzemburgh, R. D. M. (2019). Crises convulsivas em neonato com microcefalia associada à infecção pelo Zika vírus. Revista Enfermagem UERJ. 27, 1-4.

Sá, S. A. A. G., Galindo, C. C., Dantas, R. S., \& Moura, J. C. (2020). Dinâmica familiar de criança com a síndrome congênita do Zika vírus no Município de Petrolina, Pernambuco, Brasil. Cadernos de Saúde Pública. 36(2), 1-20.

Souza, W. V., Araújo, T. V. B., Albuquerque M. F. P. M., Braga, M. C., Ximenes, R. A. A., Miranda-Filho, D. B., Bezerra, L. C. A., Dimech, G. S., Carvalho, P. I., Assunção, R. S., Santos, R. H., Oliveira, W. K., Rodrigues, L. C., \& Martelli, C. M. T. (2016). Microcefalia no Estado de Pernambuco, Brasil: características epidemiológicas e avaliação da acurácia diagnóstica dos pontos de corte adotados para notificação de caso. Cadernos de Saúde Pública. 32(4), $1-8$.

Cruz, G. V. S. F., Rodrigues, F. M. C., Silva, E. M., Kantoviscki, A. L. L., \& Souza, S. G. (2019). Diagnósticos e intervenções de enfermagem a criança com síndrome congênita Zika vírus. Revista Nursing. 22(253), 2949-2955.

Queiroz, L. P. B., Barros, J. N. P., Monteiro, C. L. S. J., \& Resende, I. T. (2019). O papel da enfermagem na assistência ao neonato com microcefalia por Zika: uma revisão de literatura. Projectus. 4(1), 152-160.

Vargas, A., Saad, E., Dimech, G. S., Santos, R. H., Sivini, M. A. V. S., Albuquerque, L. C., Lima, P. M. S., Barreto, I. C., Andrade, M. E., Estima, N. M., Carvalho, P. I., Azevedo, R. S. A., Vasconcelos, R. C. O., Assunção, R. S., Frutuoso, L. C. V., Carmo, G. M. I., Souza, P. B., Wada, M. Y., Oliveira, W. K., Henriques, C. M. P., \& Percio, J. (2016). Características dos primeiros casos de microcefalia possivelmente relacionados ao vírus Zika notificados na Região Metropolitana de Recife, Pernambuco. Epidemiologia e Serviços de Saúde. 25(4),691-700. 